\title{
GASFLOW Validation with Panda Tests from the OECD SETH Benchmark Covering Steam/Air and Steam/Helium/Air Mixtures
}

\author{
Peter Royl, ${ }^{1}$ John R. Travis, ${ }^{1}$ Wolfgang Breitung, ${ }^{1}$ Jongtae Kim, ${ }^{2}$ and Sang Baik Kim² \\ ${ }^{1}$ Forschungszentrum Karlsruhe, Institut für Kern- und Energietechnik, 76021 Karlsruhe, Germany \\ ${ }^{2}$ Division of Thermal-Hydraulics and Safety Research, Korean Atomic Energy Research Institute, Yseong, \\ Daejeon 305-353, South Korea
}

Correspondence should be addressed to Peter Royl, royl@iket.fzk.de

Received 19 November 2008; Revised 2 March 2009; Accepted 22 April 2009

Recommended by Walter Ambrosini

The CFD code GASFLOW solves the time-dependent compressible Navier-Stokes Equations with multiple gas species. GASFLOW was developed for nonnuclear and nuclear applications. The major nuclear applications of GASFLOW are 3D analyses of steam/hydrogen distributions in complex PWR containment buildings to simulate scenarios of beyond design basis accidents. Validation of GASFLOW has been a continuously ongoing process together with the development of this code. This contribution reports the results from the open posttest GASFLOW calculations that have been performed for new experiments from the OECD SETH Benchmark. Discussed are the steam distribution tests 9 and 9bis, 21 and 21bis involving comparable sequences with and without steam condensation and the last SETH test 25 with steam/helium release and condensation. The latter one involves lighter gas mixture sources like they can result in real accidents. The helium is taken as simulant for hydrogen.

Copyright (C) 2009 Peter Royl et al. This is an open access article distributed under the Creative Commons Attribution License, which permits unrestricted use, distribution, and reproduction in any medium, provided the original work is properly cited.

\section{Introduction}

The CFD code GASFLOW solves the time-dependent compressible Navier-Stokes Equations with multiple gas species [1]. It models two-phase effects of condensation and/or vaporization in the fluid mixture region with the assumption of the homogeneous equilibrium (HEM) model, two-phase heat transfer to and from walls and internal structures by convection and mass diffusion, and the chemical kinetics of hydrogen combustion with general ignitor models and catalytic recombination. The code is applied in the 3D analysis of steam/hydrogen distribution in various PWR containments to simulate scenarios of beyond design basis accidents. Validation of GASFLOW with thermal hydraulic experiments that simulate such scenarios or some of their aspects is an ongoing effort with involvement of all members of the GASFLOW users group, which comprises industrial and research partners. GASFLOW successfully participated in the blind and in the open posttest analysis of the international standard problem ISP47 [2]. The OECD Panda SETH experiments and their results, which are accessible to members of the funding countries, have further widened the database for predicting such containment-related severe accident scenarios. The tests were designed by the Swiss Paul Scherrer Instiute and performed in their Panda facility [3]. GASFLOW analyses of some of these tests have been jointly made by the Korean Atomic Energy Research Institute (KAERI) and by Forschungszentrum Karlsruhe. This contribution will report the results from the open posttest GASFLOW calculations that have been performed for the steam distribution tests 9 and 9bis, 21 and 21bis involving comparable sequences without and with steam condensation and for the latest Panda SETH test 25 with steam/helium release and condensation. The latter one involves lighter gas mixture sources like they can result in real accidents. The helium is taken as the simulant for hydrogen. Figure 1 shows one of the 3D cartesian GASFLOW facility models applied in the analysis of these tests.

\section{Simulated Panda Seth Tests}

The OECD SETH project has initiated a series of 25 tests in the two rooms DW1 and DW2 of the large-scale 


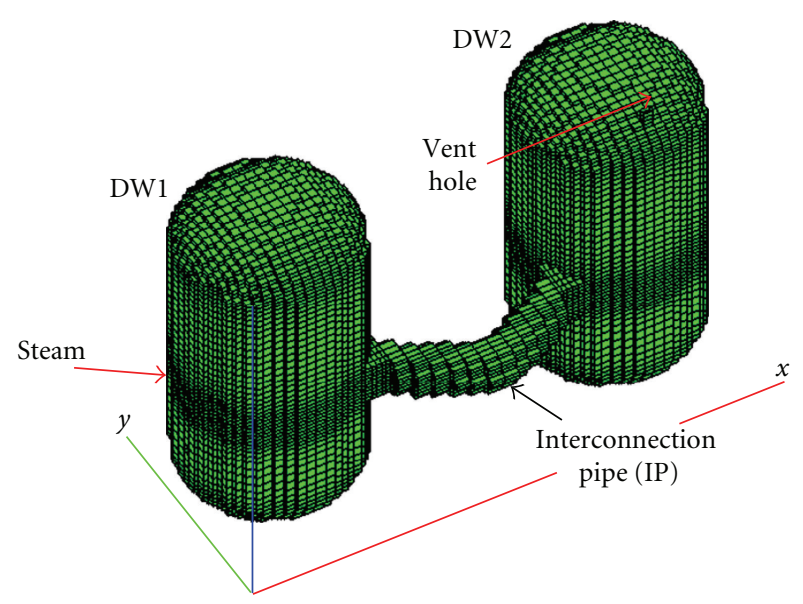

Figure 1: Fine 3D model of the Panda facility.

thermal hydraulic facility Panda to simulate mixing and stratification phenomena in a larger multicompartment gas volume approaching the dimension of actual containment compartments. Figure 2 gives an overview of the 6 experiments from this series that were simulated with GASFLOW. The two vessels DW1 and DW2 have the same volume of $90 \mathrm{~m}^{3}$ each and are all initially filled with dry air. A feeding vessel DW1 is connected to the receiving vessel DW2 through a bended pipe with a large diameter. In all analyzed tests except test 25 a vent hole was active in the dome of DW2 that maintained a constant pressure of 1.3 bar. Tests 9 and 9bis investigated the spreading of a buoyant steam plume over these two compartments that resulted from a low-velocity horizontal injection into the lower region of DW1. Tests 21 and 21 bis investigated the spreading from an axial steam injection high in the dome of DW1. Tests 9 and 21 were run with higher steam temperatures. The whole facility was preheated to a high-enough temperature to suppress steam condensation. Tests 9 bis and 21 bis were run in a less-preheated facility with a lower steam temperature that allowed for steam condensation. The 9 and 21 series tests all applied the same constant rate of steam injection of $14 \mathrm{~g} / \mathrm{s}$. They are well suited for testing condensation models currently implemented in CFD codes. The test facility is insulated but can absorb heat with its heat capacity. Test 25 is the final test from the SETH series. It simulated a sequence of steam/helium injections into the air-filled facility initially at room temperature [4]. The gas spreads into a dead end vessel DW2 because the vent valve in DW2 is closed. Gas venting in test 25 occurs through a vent pipe in DW1 below the source and interconnecting pipe. This vent pipe connects to the large wet well (WW) volume. The vent pressure in this test is recorded. It rises monotonically with time and can be applied as a pressure boundary condition in the analysis instead of the constant vent pressure in DW2. In test 25 only the pressure but not the volume flow rates at the entrance to the vent pipe could be measured. The problem times to analyze the 9 and 21 series tests were 7000 seconds. Test 25 involved two equally long phases of 7200 seconds with a steam/helium injection in phase 1 followed by a pure steam injection in phase 2 . The total problem time to analyze for this test is 14400 seconds.

\section{Gasflow Models of the Test Facility}

The facility has been simulated in coarse (13000), fine (115 000), and extremely fine (365 000) 3D Cartesian meshes (Figure 3). A fine mesh with 115,351 cells was developed with a smaller number of blocked cells (orientation I). The source had to be split up into equal $x$ and $y$ components with this mesh to achieve the proper injection angle of 45 degrees because the steam injection was not on the $x$-coordinate axis. The coarse model for orientation II simulated the injection along the $x$-axis. It had 24,180 cells with nearly equidistant $x y z$ meshes of $33 \mathrm{~cm}$ and a higher fraction of blocked cells. The finest grid model for orientation II had 365,040 cells with fine axial grid sizes of $5 \mathrm{~cm}$ between the injection location and the horizontal sensor plane at $380 \mathrm{~cm}$ and fine $x y$ meshes of $5 \mathrm{~cm}$ on the source side of DW1. Good agreement with the test data was found with all meshes. Comparisons showed that neglecting the bend of the connection pipe and modeling a straight pipe with a length of $5 \mathrm{~m}$ between the vessels has no strong impact on the results. To economize on the CPU time we then ran most tests with the straight pipe model which allows to simulate the tests with only 13,182 numerical cells of nearly equidistant meshes of $33.33 \mathrm{~cm}$. For the studied tests, coarse and fine meshes gave quite good overall results as long as condensation did not come into play. With condensation we obtained nearly mesh independent overall results when the heat transfer with the applied wall functions was enhanced in the ratio of the coarse and fine wall mesh. Analysis of test TH13 from ISP47 showed a similar agreement when going from a fine to a coarse mesh with this type of wall function adjustment. The large fractions of structure surfaces in the facility, that have mostly stagnant flow conditions during the test justifies this enhancement. Like in all other CFD codes that apply wall functions to avoid resolving the boundary layer there is still a need for a wall function formulation that gives a mesh-independent heat transfer in the transition to stagnant flow conditions. The automatic wall function option in CFX could not be demonstrated as a solution so far in problems involving steam condensation. GASFLOW applies a specific set of wall functions together with an explicit setting for no slip conditions on all structures. But these wall functions are also largely valid for forced flow conditions only. All injections are simulated from a source reservoir with a single cell with a single injection node. The structure model simulates the heat capacity of a $2 \mathrm{~cm}$ steel vessel that is insulated with a $20 \mathrm{~cm}$ layer of rock wool on the outside with one-dimensional heat conduction and adiabatic boundary conditions using 44 heat conduction nodes. An area balance prior to the simulation adjusts the surface of the stair-stepped Cartesian model to the specified facility data. A first-order time integration and a second-order (van Leer) advection scheme is applied and the use is made of the standard k-e turbulence model in all simulations. Table 1 gives an overview of the analyzed tests, the key test parameters, and the applied meshes. 


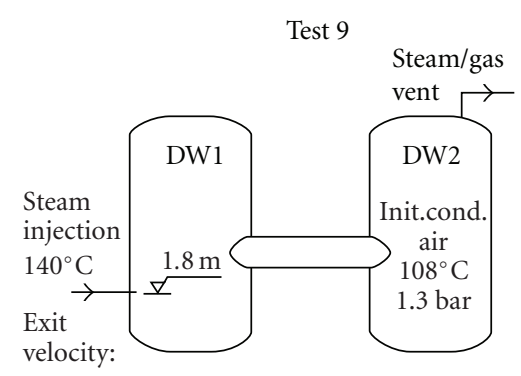

Test 9: $1 \mathrm{~m} / \mathrm{s}$

Test $16: 3 \mathrm{~m} / \mathrm{s}$

Test $17: 5 \mathrm{~m} / \mathrm{s}$

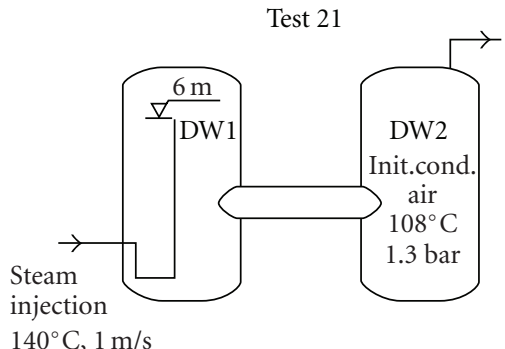

$140^{\circ} \mathrm{C}, 1 \mathrm{~m} / \mathrm{s}$

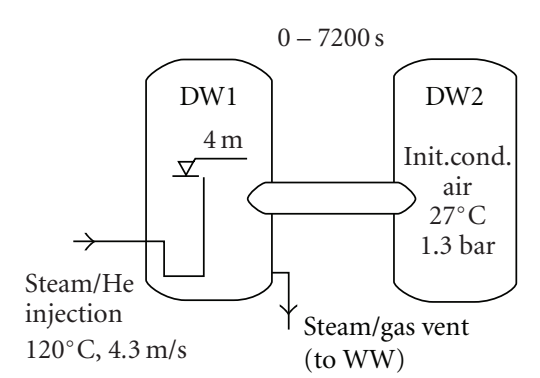

Test 9bis

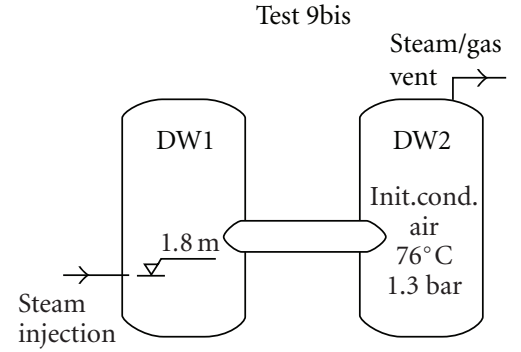

$108^{\circ} \mathrm{C}, 1 \mathrm{~m} / \mathrm{s}$

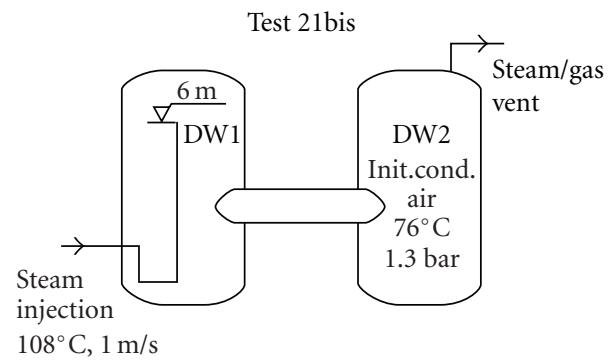

Test 25

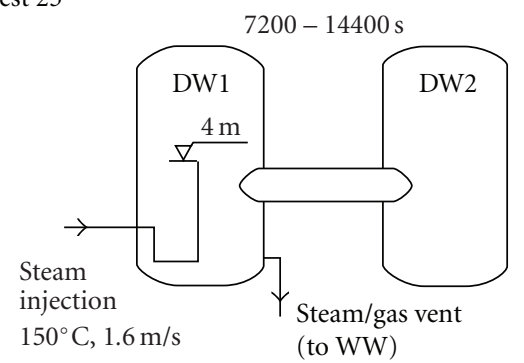

FIgURE 2: SETH tests analyzed with GASFLOW.
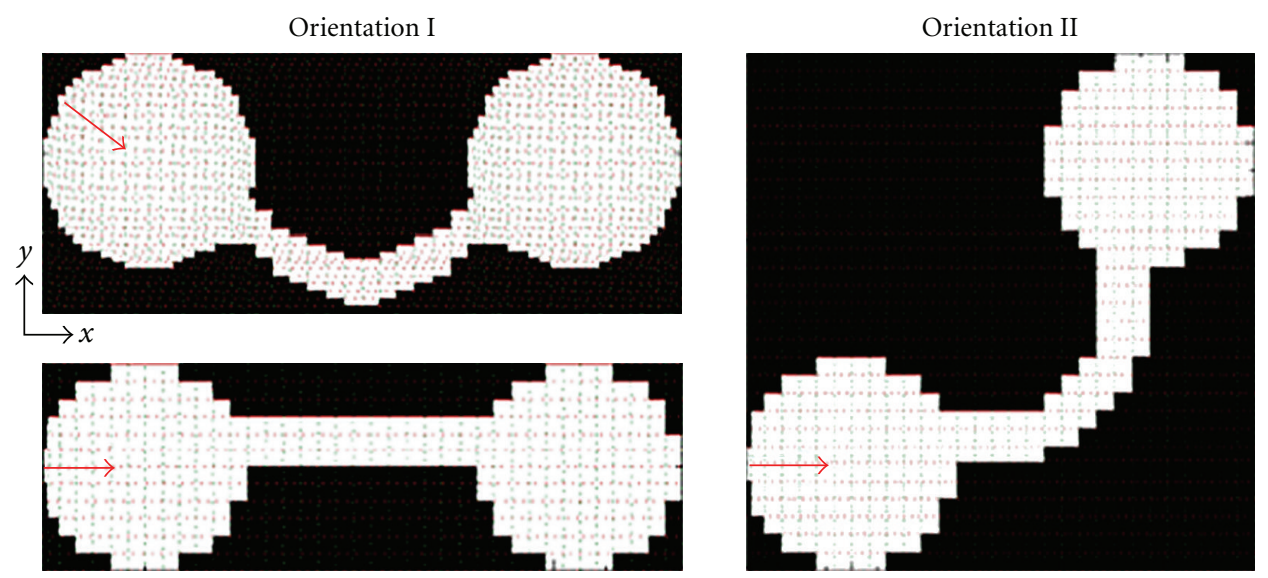

\begin{tabular}{|} 
Straight pipe \\
\begin{tabular}{|c|c|c|}
\hline Mesh & Orientation & Cells \\
\hline \multirow{2}{*}{ Coarse } & I & 15,392 \\
\cline { 2 - 3 } & II & 24,180 \\
\cline { 2 - 3 } & Straight pipe & 13,182 \\
\hline Fine & I & 115,351 \\
\hline Finest & II & 365,040 \\
\hline
\end{tabular}
\end{tabular}

FIgURE 3: Applied horizontal meshes. 
TABLE 1: SETH test parameters and GASFLOW facility models.

\begin{tabular}{|c|c|c|c|c|c|c|c|c|}
\hline test & $\begin{array}{c}\text { To vessel } \\
{[\mathrm{C}]}\end{array}$ & Model & $\begin{array}{c}\text { steam } \\
\text { source }[\mathrm{g} / \mathrm{s}]\end{array}$ & $\begin{array}{c}\text { Helium } \\
\text { source g/s }\end{array}$ & $\begin{array}{l}\text { inj. velocity } \\
{[\mathrm{m} / \mathrm{s}]}\end{array}$ & $\begin{array}{c}\text { steam } \\
\text { Temp. [C] }\end{array}$ & $\begin{array}{c}\text { Steam } \\
\text { condensation }\end{array}$ & $\begin{array}{l}\text { Problem } \\
\text { Time [S] }\end{array}$ \\
\hline \multirow[t]{4}{*}{9} & \multirow[t]{4}{*}{108} & coarse & \multirow[t]{4}{*}{14} & \multirow[t]{4}{*}{ - } & \multirow[t]{4}{*}{1} & \multirow[t]{4}{*}{140} & \multirow[t]{4}{*}{ no } & 7000 \\
\hline & & str. pipe & & & & & & $\overline{7000}$ \\
\hline & & fine & & & & & & 4000 \\
\hline & & finest & & & & & & 250 \\
\hline \multirow[t]{4}{*}{ 9bis } & \multirow[t]{4}{*}{76} & coarse & \multirow[t]{4}{*}{14} & \multirow[t]{4}{*}{ - } & \multirow[t]{4}{*}{1} & \multirow[t]{4}{*}{108} & \multirow[t]{4}{*}{ yes } & 7000 \\
\hline & & str. pipe & & & & & & 7000 \\
\hline & & fine & & & & & & 4000 \\
\hline & & finest & & & & & & 250 \\
\hline 21 & 108 & str. pipe & 14 & - & 1 & 140 & no & 7000 \\
\hline 21bis & 76 & str. pipe & 14 & - & 1 & 108 & yes & 7000 \\
\hline 25 & 27 & str. pipe & 64 & 8 & 4.3 & 120 & yes & 14400 \\
\hline
\end{tabular}

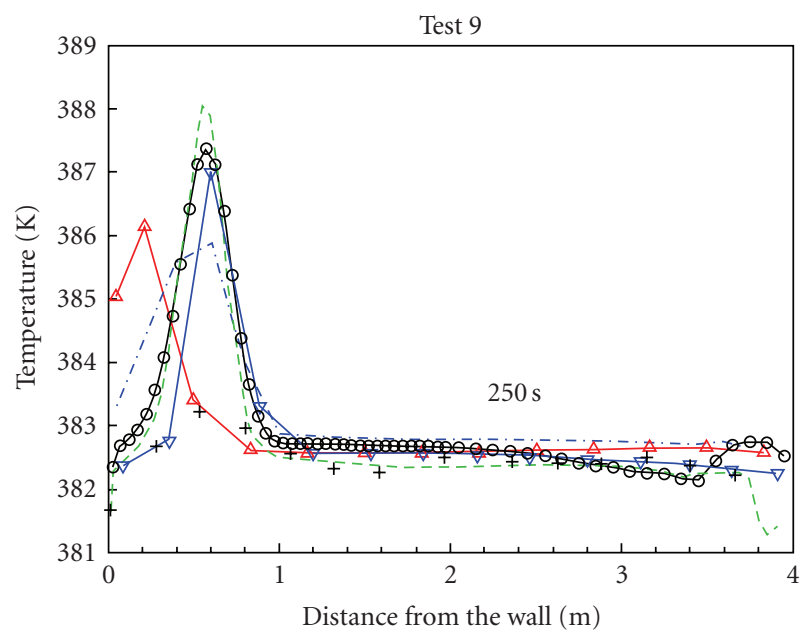

$\begin{array}{ll}+ \text { Experiment } & \triangle \text { GASFLOW, coarse mesh } \\ --- \text { CFX-4, 700 k, k-e } & \square \text { GASFLOW, fine mesh } \\ -.- \text { GOTHIC } & - \text { GASFLOW, finest mesh }\end{array}$

(a)

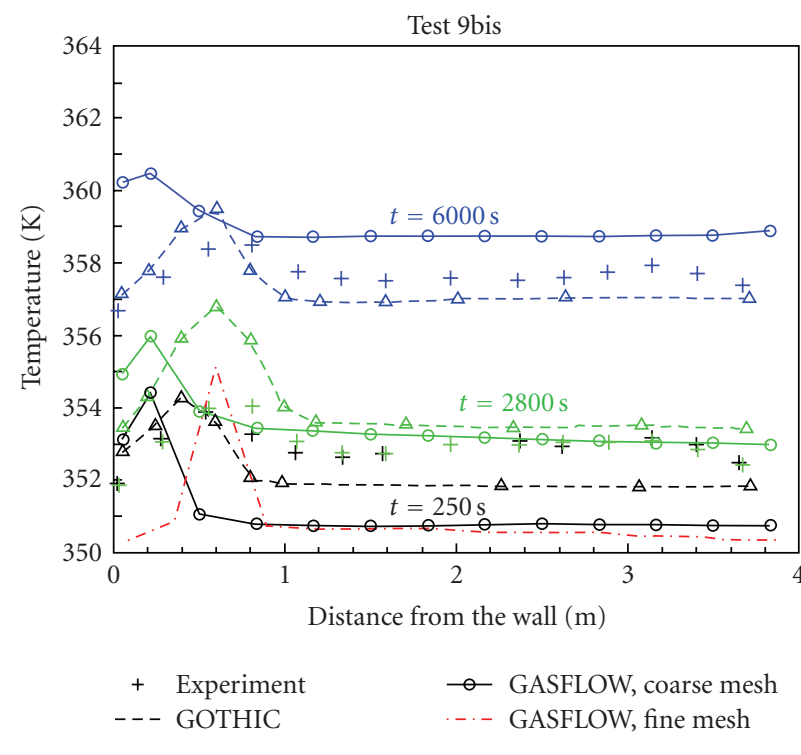

(b)

FIgURE 4: Horizontal temperature profiles $2 \mathrm{~m}$ above injection jet.

\section{Results}

4.1. Tests 9 and 9bis. The fine and finest mesh simulations of these tests all adapted the mesh to make the faces of the feeding cells for the horizontal buoyant plume to match the area of the injection orifice to inject the steam with its correct injection momentum. In test 9 with the finest mesh the horizontal temperature profile $2 \mathrm{~m}$ above the injection location (Figure 4) shows the same location and height of the peak at 250 seconds as the CFX-4 simulation with the finest mesh of 700,000 cells. Calculations with a coarse GOTHIC model with 26,000 cells give about the same peak location but lower peak temperatures [5-7]. The coarse mesh GASFLOW model injects with a too low injection momentum and gives the peak closer to the wall with similar peak temperatures as GOTHIC. More mixing of the momentum, mass, and energy occurs in the coarser mesh. So far all CFD analyses of test 9 predict higher than measured peak temperatures at the comparison point. The reasons for this are not yet understood. Condensation does not affect modeling of test 9 in any calculation. Some influence could come from radiation cooling of the hotter steam plume, which was not accounted for in any calculation. The measured temperature peaks from test 9bis at 250 seconds are better predicted. Over predictions are again seen around 2800 and 6000 seconds. The tail values outside the peak are in better agreement than the peaks.

In the early test phase the results with the fine and coarse mesh showed significant differences in the velocity profiles. But these did not alter the overall convective flow between the two test vessels, because local mesh effects generally smeared out during the deflection of the buoyant flow in the dome region. The axial profiles of the steam concentrations along 

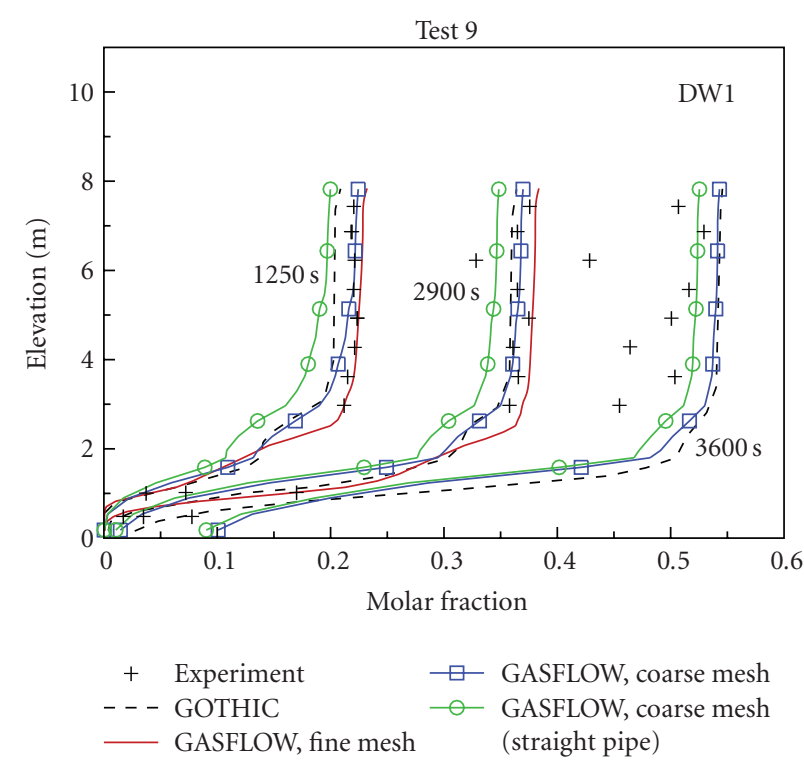

(a)
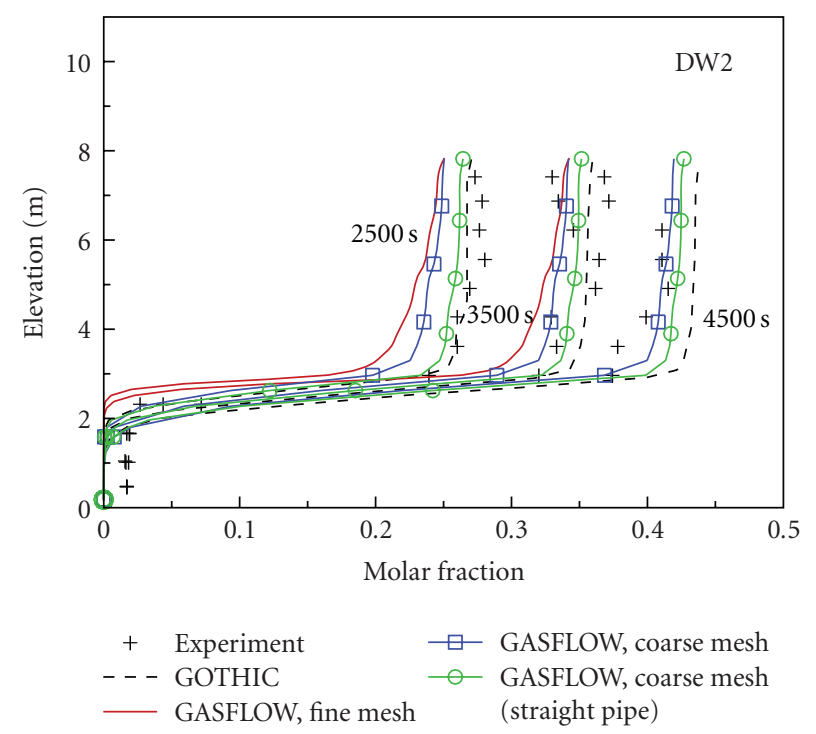

(c)
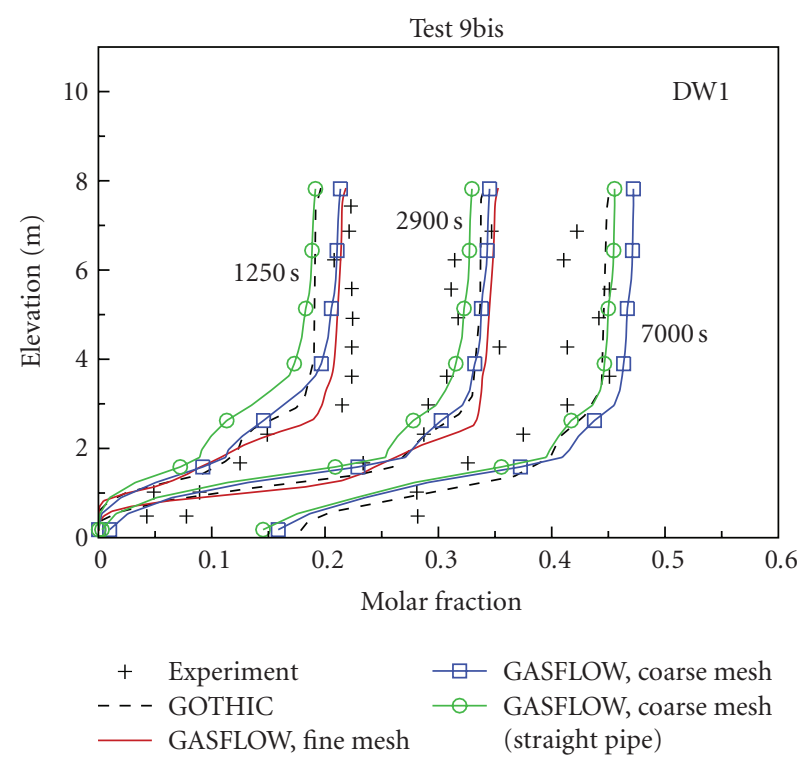

(b)

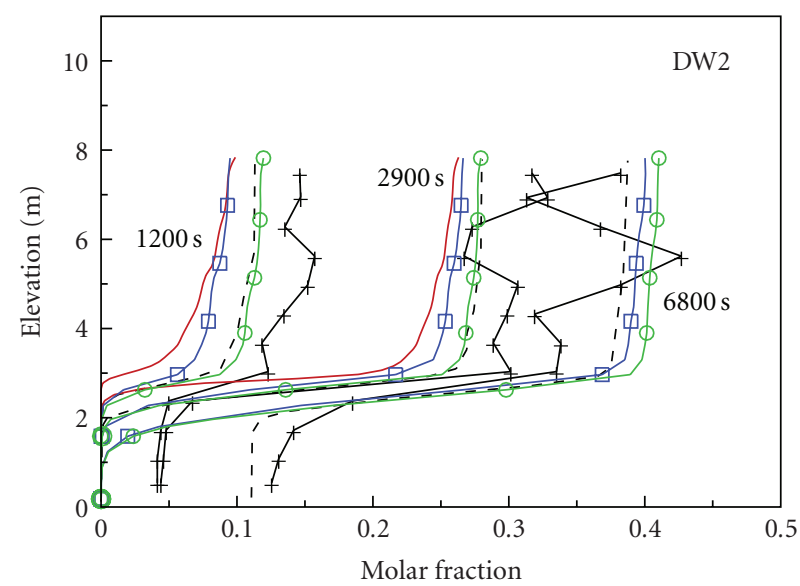

$\begin{array}{lll}+ \text { Experiment } & \square & \text { GASFLOW, coarse mesh } \\ --- \text { GOTHIC } & - & \text { GASFLOW, coarse mesh } \\ \text { (straight pipe) } & \text { GASFLOW, fine mesh } & \end{array}$

(d)

FIgURE 5: Axial steam concentration profiles in the centerline of DW1 and DW2.
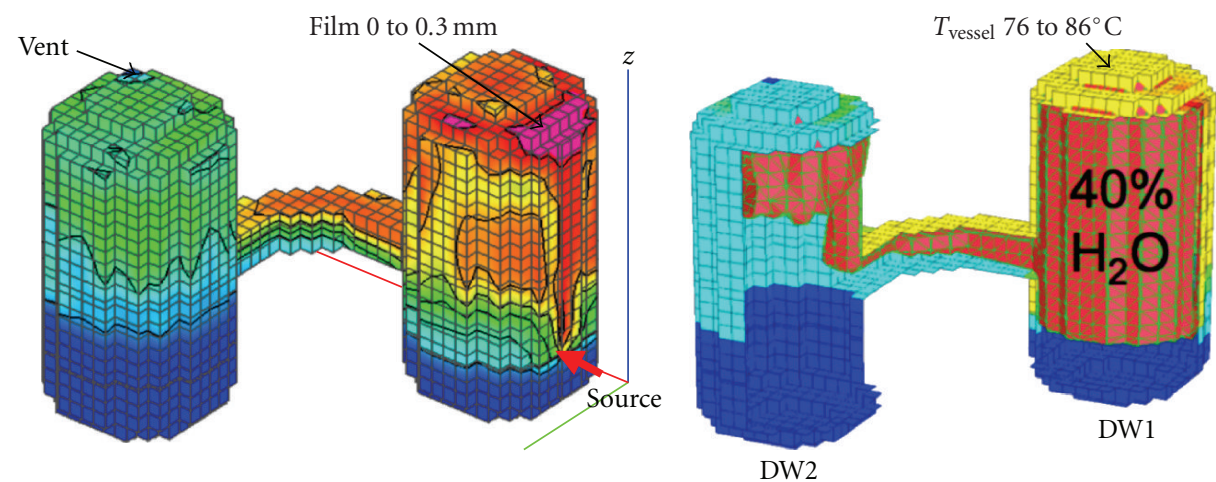

FIgURE 6: Test 9bis final condensate film, steam cloud, and vessel temperature (7000 seconds). 


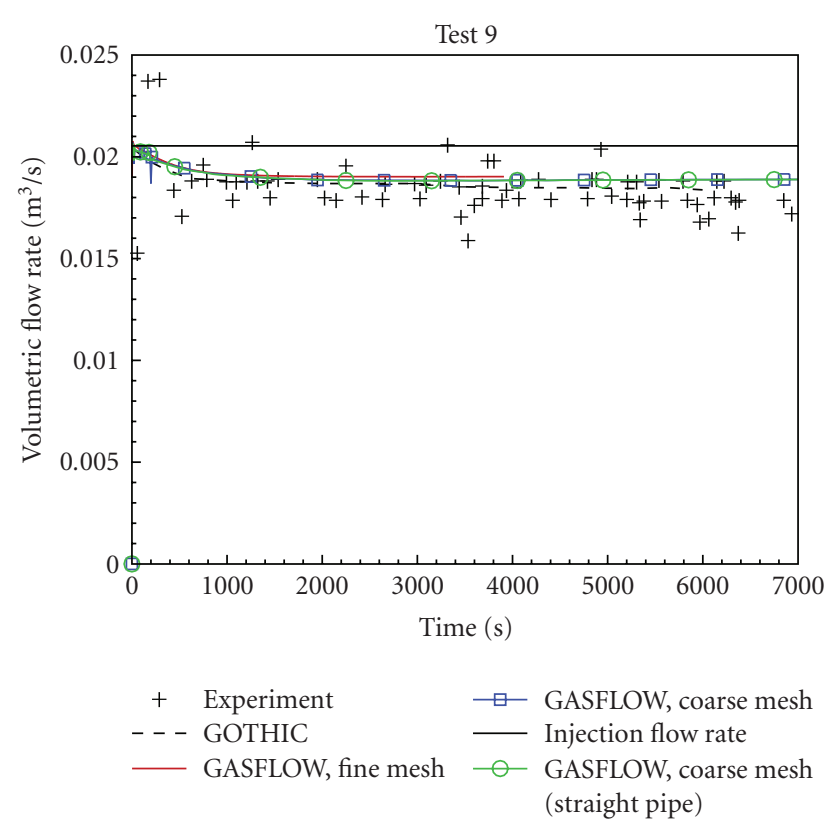

(a)

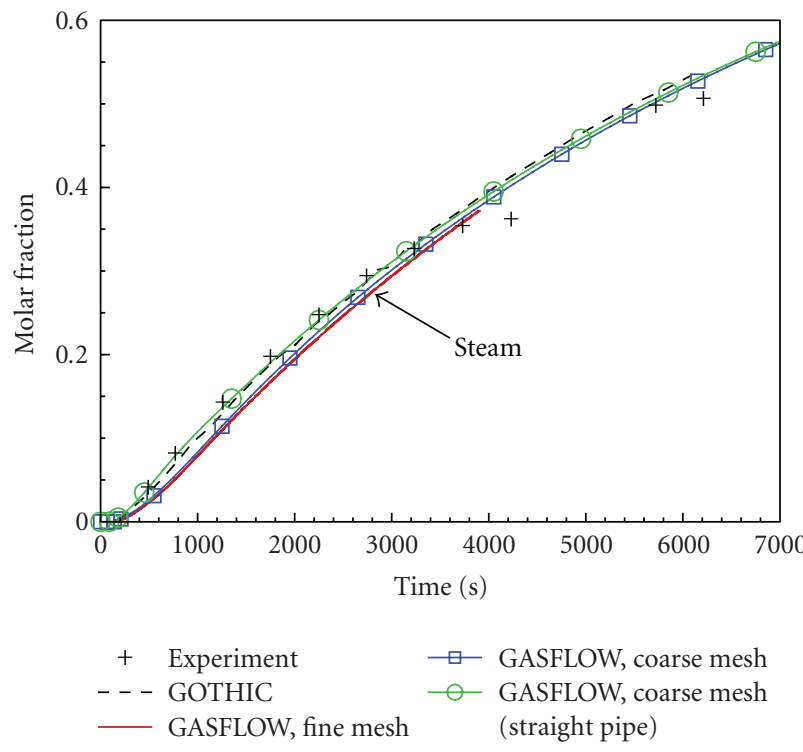

(c)

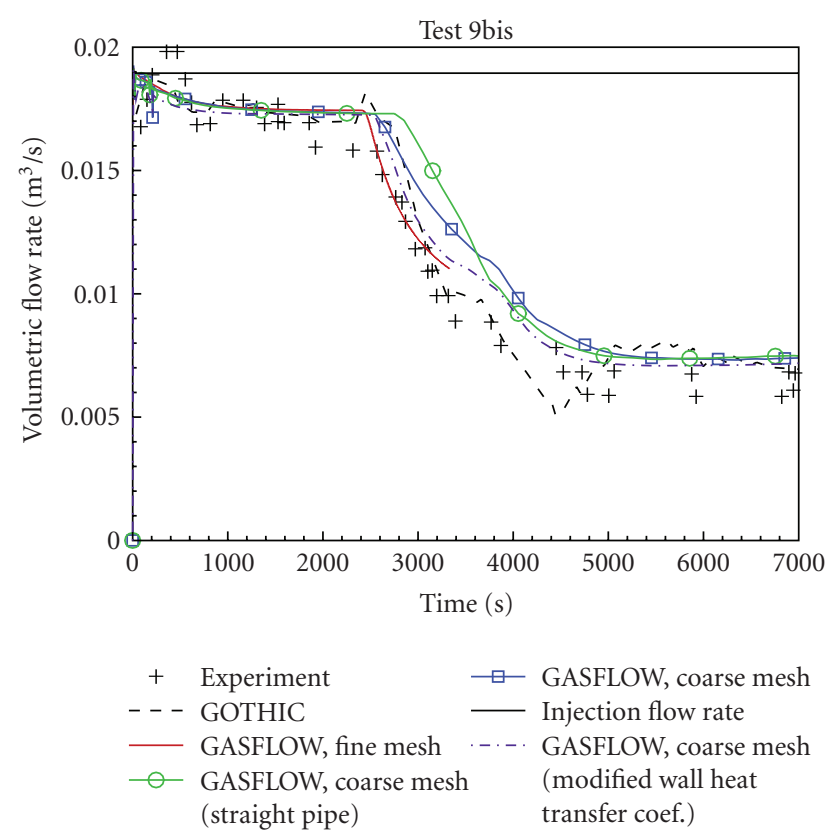

(b)

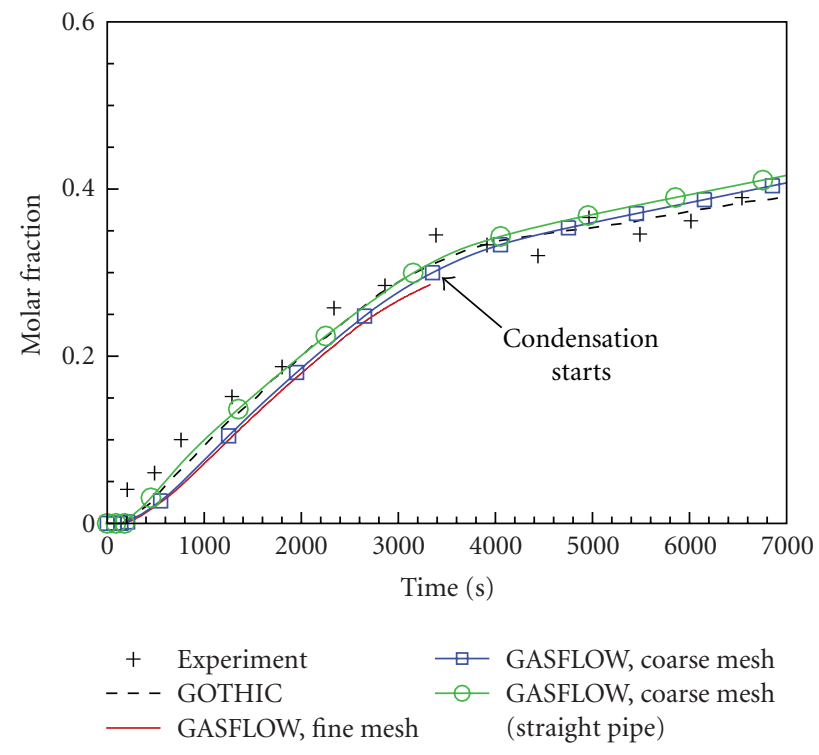

(d)

Figure 7: Volume rate and steam concentration at the vent (test 9 and 9bis).

the centerline of DW1 and DW2 (Figure 5) show acceptable agreements with the test data. The straight pipe model gives a little more spreading into DW2 with lower concentrations in DW1. The results for the coarse and fine mesh model with the bended connection pipe are closer. Test 9bis with steam condensation shows higher steam concentrations near the bottom of the facility. They are likely to originate from the vaporization of a draining film into the dry air region below the steam cloud [5]. GASFLOW only simulates a static film and shows no film in DW2 below the connection pipe in the final snap shot with the coarse 3D model (Figure 6) that also gives the $40 \%$ steam cloud together with the more elevated vessel temperature in the regions with higher steam concentrations.

The recorded volume flow rates at the vent in DW2 rapidly reduce over the inlet flow to some plateau values that reflect the cooling of the injected steam by mixing with air (Figure 7). A further decay to a second plateau occurs in test 9 bis after onset of condensation around 3000 seconds. This plateau is controlled by the constant pressure of 1.3 bar at the vent and predicted well. Thermodynamically this pressure enforces a quasistationary condensation rate with saturated conditions. But the transition to the second plateau is too slow with the coarse model while the fine mesh 


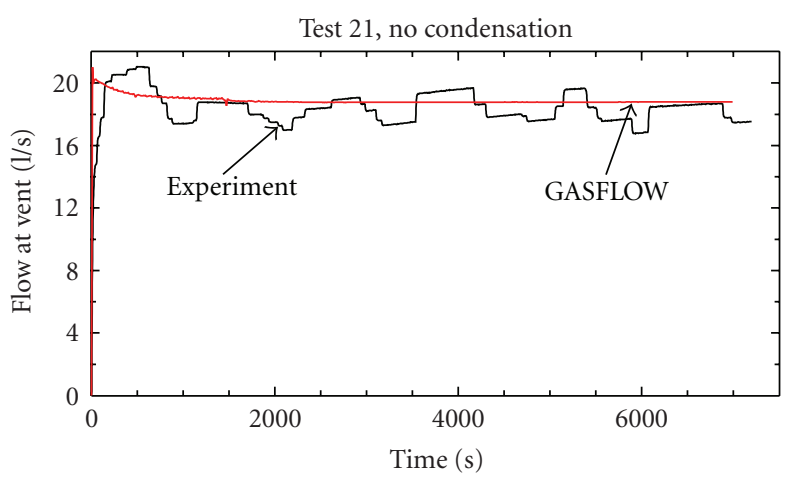

(a)

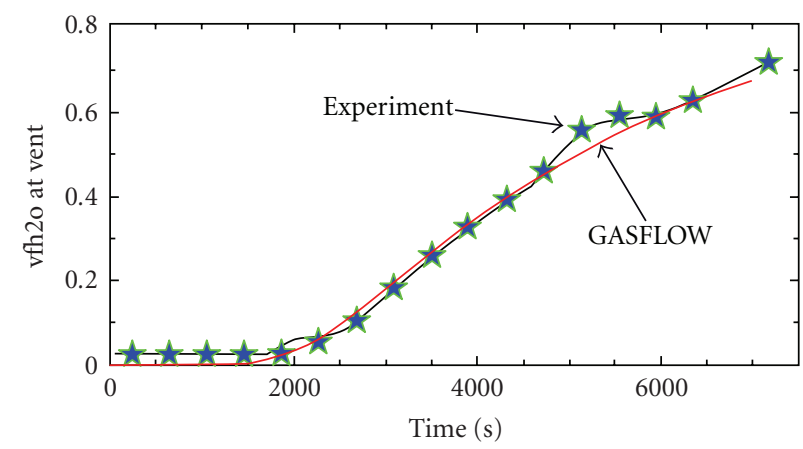

(c)

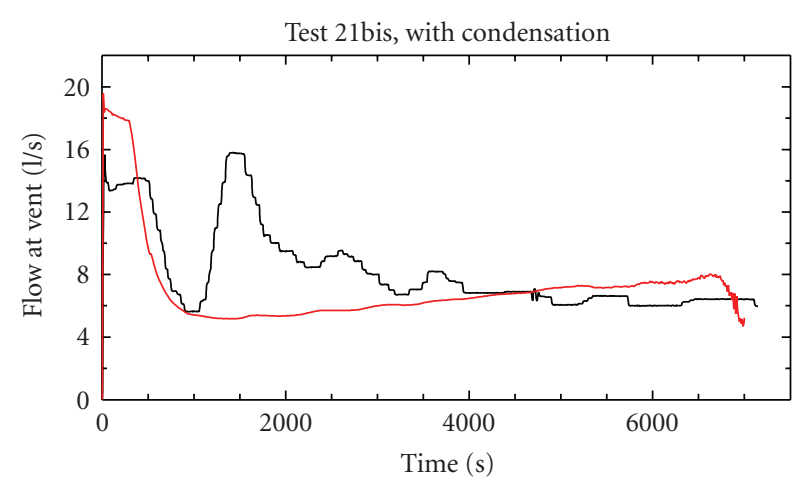

(b)

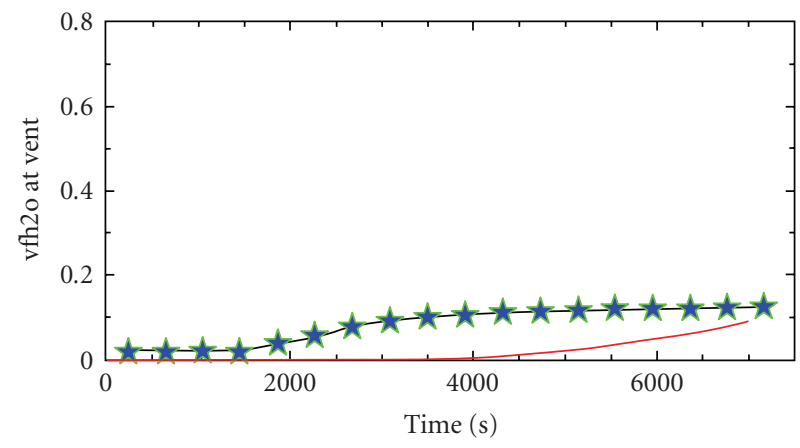

(d)

FIgURE 8: Volume rate and steam concentration at the vent (test 21 and 21bis).

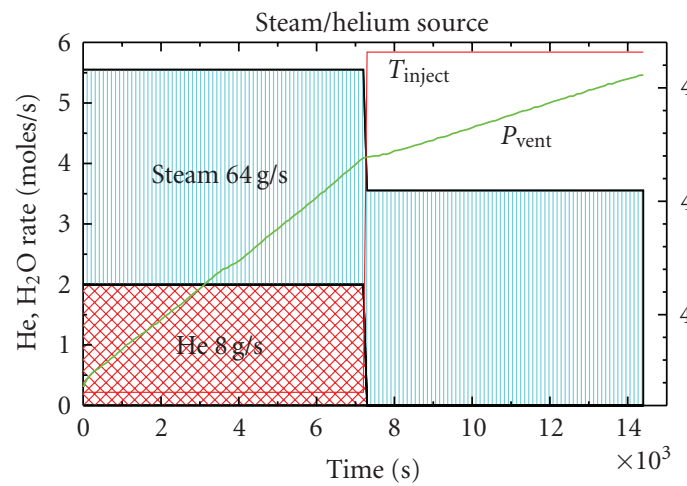

(a) $10^{3}$

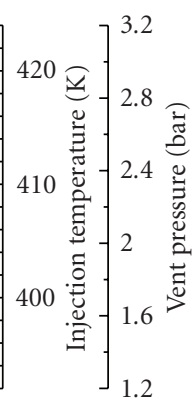

Figure 9: Source and boundary conditions for test 25.

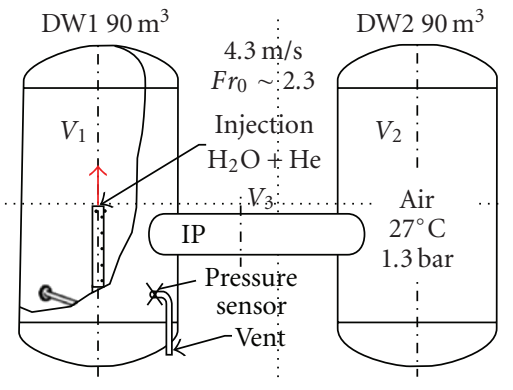

(b) results follow the test data more closely. The transition in the coarse mesh simulation in which the heat transfer was enhanced by the ratio of the coarse and fine wall mesh (factor 2) falls right on the result of the fine mesh. The measured steam concentration at the vent (lower graph in Figure 7) is well predicted in GASFLOW with the coarse and fine meshes. It shows similar initial increases and a pronounced slowing down of the growth in test 9bis after condensation onset. Calculated steam distributions in DW1, in the interconnection pipe, and in DW2 show a somewhat better agreement for the coarse models with the bended versus the straight pipe. But from the tendency both models capture the correct phenomenology.
4.2. Tests 21 and 21bis. The GASFLOW simulation of test 21 with the straight pipe model also gives excellent predictions for the volume rates and steam concentrations at the vent in DW2 (Figure 8) in particular for the time of steam arrival. With the direct impingement of steam in the dome condensation in test 21 bis comes very early and the volume rates reduce more rapidly than in test 9 bis. Only the regular wall functions were applied and no special model was available to simulate the heat and mass transfer from the impinging steam jet. Steam condensation heats up the dome, and the volume rate at the vent valve goes through a minimum when the dome structure is saturated and cannot condense so much steam anymore. 


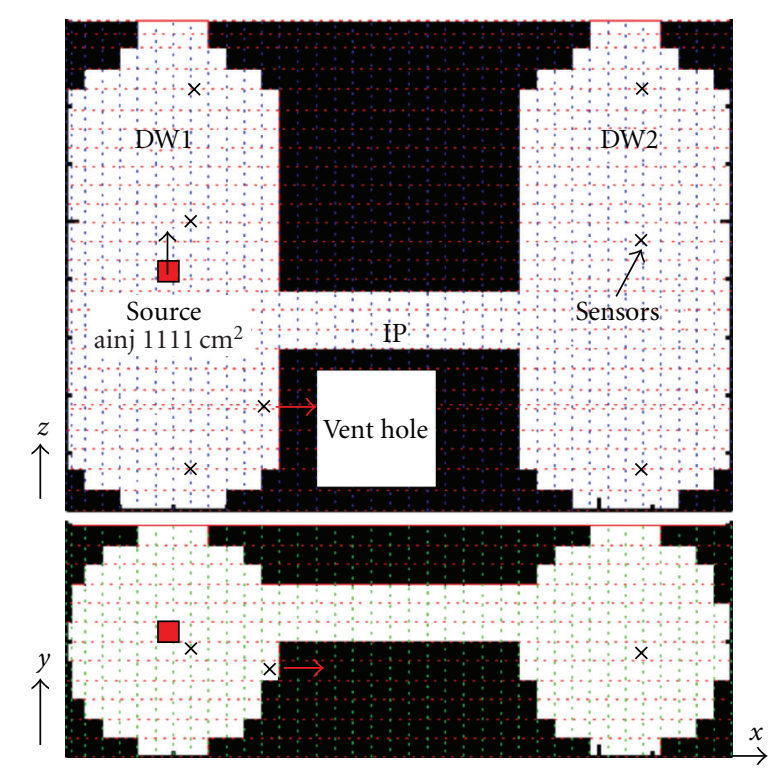

Figure 10: 3D Cartesian GASFLOW model of the Panda SETH facility for analysis of test 25 (straight pipe model).

After this, GASFLOW predicts it to rise only gradually as the steam cloud propagates into the vessel regions below the larger dome surface. Initially the test data show a similar behavior but then rise again shortly to an intermediate peak before they decay to similar rates as calculated in GASFLOW. Andreani [5], Paladino [4] attribute this peak to an additional volume source from the vaporization of the condensate film draining on the preheated structures into regions with dry air. This interpretation is consistent with the earlier steam arrival in the test relative to the much later arrival predicted in GASFLOW, which does not model a moving film. The final steam concentration from GASFLOW at 7000 seconds approaches the test data well. The quasistationary condensation then reflects the thermodynamic boundary condition set by the vent valve pressure. The late drop of the volume flow in test 21 bis after 6500 seconds marks the onset of condensation in DW2 where the steam concentration eventually exceeds the limit for condensation.

4.3. Test 25. The steam/helium distribution test 25 investigates the distribution of light gas mixtures with condensing steam in air over two rooms with a dead end like it can occur in containment rooms in severe accidents [8]. Figure 9 gives the applied steam/helium source and the pressure boundary in this test with an axial injection near the mid height of DW1. The initial injection velocity is $4.3 \mathrm{~m} / \mathrm{s}$. Injection starts with a Froude number of 2.3 , which is characteristic for a rising plume whose buoyancy dominates over the injection momentum already at short distance from the source. The vent is located in the lower region of DW1 far below the injection source and the interconnection pipe (IP). GASFLOW uses a pressure boundary condition at the location of this vent with the recorded monotonic increase of the pressure from Figure 9.
Figure 10 shows the Cartesian model with the straight interconnection pipe that was used in the calculation. A refinement at the top also simulates the man-hole region. The coarse model uses 12,300 cells $(39 x, 13 y$, and $28 z$ nodes) and simulates the total free gas volume of $180 \mathrm{~m}^{3}$ with an average cell volume of 32 liters. The interconnection pipe is simulated three dimensionally with a cross section of $3 \times 3$ cells. The red arrow marks the location of the vent hole where the pressure boundary condition from Figure 9 was applied. The red box gives the location of the injection cell. The source gas is injected from a sealed-off reservoir cell in the $3 \mathrm{D}$ fluid mesh with a time-dependent steam/helium composition using a velocity boundary condition at the open feeding side on the top of the source cell. GASFLOW has an option to reduce the area of the feeding source cell to inject with the correct injection momentum. But the cell surface of $1111 \mathrm{~cm}^{2}$ in the coarse mesh is much larger than the $314 \mathrm{~cm}^{2}$ cross section of the $20 \mathrm{~cm}$ injection pipe. The use of this option introduced a too strong air entrainment into the fluid cell right above the source. This diluted the steam/helium mixture close to the source and the concentration of the helium layer built up from steam condensation in the dome did not reach the measured high level. For the buoyancy dominated plume rise in this experiment it turned out better to use the cell face from the coarse mesh without the area reduction and neglect the error from a too low injection momentum.

Figure 11 compares the calculated and measured helium concentrations in the dome, middle and low regions of DW1 and DW2 (locations see Figure 10). The two variations apply the mesh face of $1111 \mathrm{~cm}^{2}$ (solid line) and the reduced area of $314 \mathrm{~cm}^{2}$ (dashed). The initial helium volume fraction in the source gas is $36 \%$. As the source plume rises to the dome, steam condenses on the cold vessel, which increases the helium volume fraction. More and more helium accumulates in the dome and builds up a stratified highconcentration helium layer that isolates itself and prevents the further addition of source gas and energy from below. The stratified layer is not affected when the steam/helium/air mixture below flows over into DW2 after 2000 seconds, which temporarily reduces the helium volume fraction in the middle region of DW1. Too much air entrainment due to the local reduction of the cell area prevented the buildup of this layer and gave more mixed concentrations in the middle and upper region of DW1. It also caused a faster increase of the helium concentration in DW2. The gas flowing over into DW2 has already a reduced steam content and nearly all steam that is brought into the cold DW2 condenses. This builds up another low-density self-insulating highconcentration helium layer also in DW2 that is even thicker than in DW1 with almost the same helium concentrations in the dome and middle region. The switch to a pure steam injection after 7200 seconds has nearly no impact on the stratified layers. They are predicted to remain stable throughout the analysis. The steam only dilutes the helium concentration in the middle region. GASFLOW predictions without the area reduction are in very good agreement with the test data. The temporarily higher concentration 


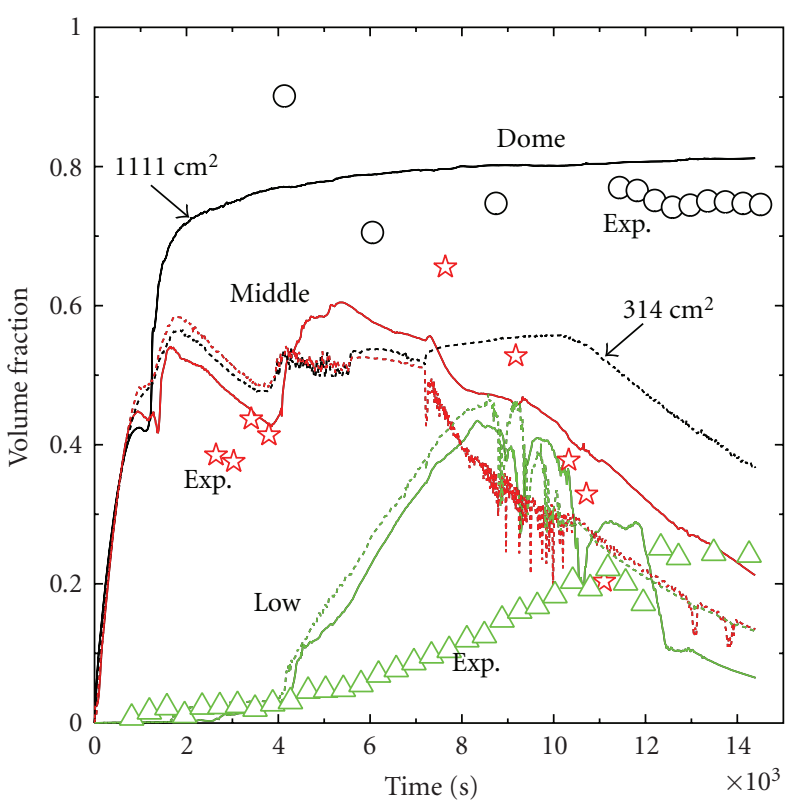

(a)

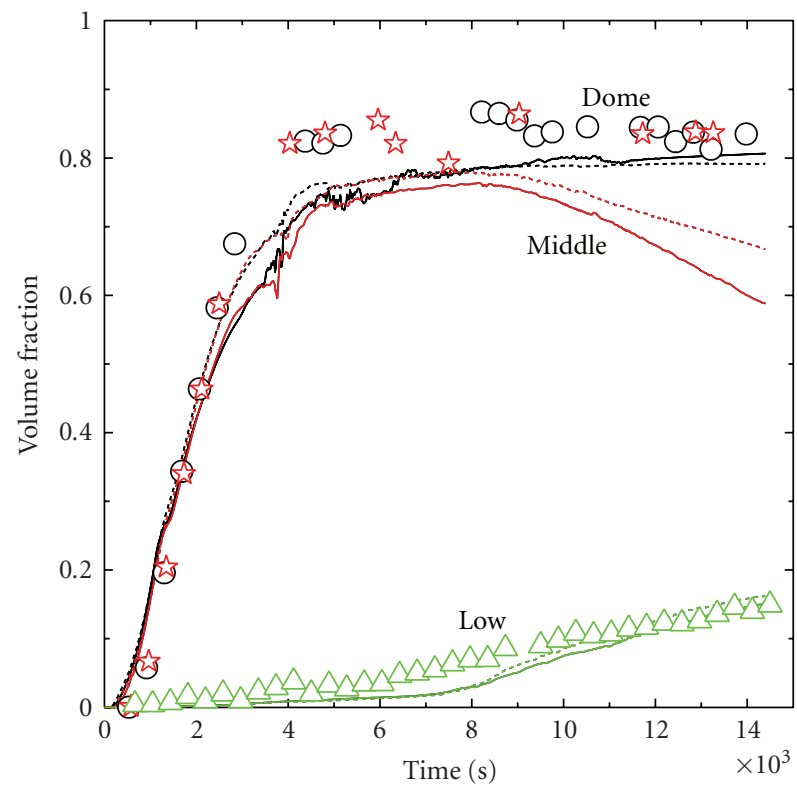

(b)

Figure 11: Helium concentrations (a) DW1 and (b) DW2 in test 25.

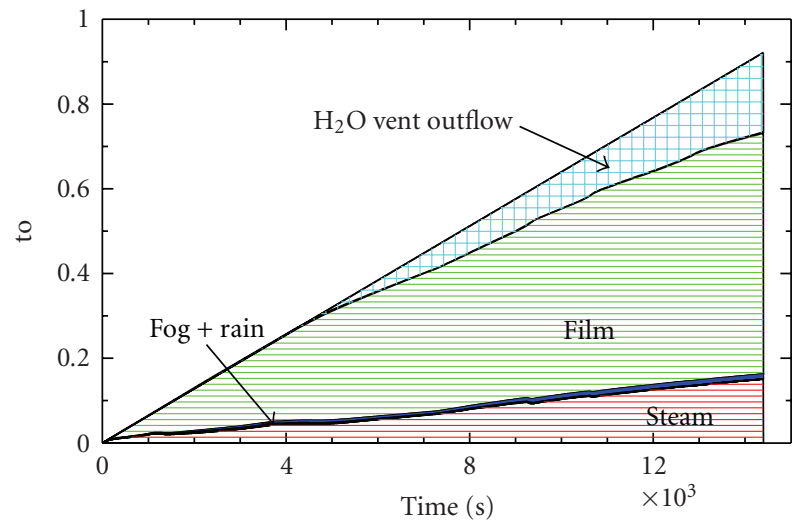

FIgURE 12: Mass balance of water and steam for test 25.

predicted in the lower region of DW1 indicates a stronger than measured helium increase that starts after 4000 seconds.

The high helium volume fraction developing in the stratified cloud has a too low density to be eroded from the heavier mixture with the released steam below. The THAI test HM2 during which a hydrogen cloud was gradually eroded from a steam release below [9] only had 35 volume \% hydrogen and smaller density differences between the steam and the light gas cloud. The parametric handling of fog rainout from bulk condensation sensitively impacted on the erosion kinetics in the THAI test. Only small amounts of fog are predicted for test 25, most steam condenses as film on the structure. Figure 12 gives the $\mathrm{H}_{2} \mathrm{O}$ mass balance for test 25. The steam loss at the vent pipe starts after about 4000 seconds. Film draining was not simulated in test 25 . Like in most containment simulations it should have a small

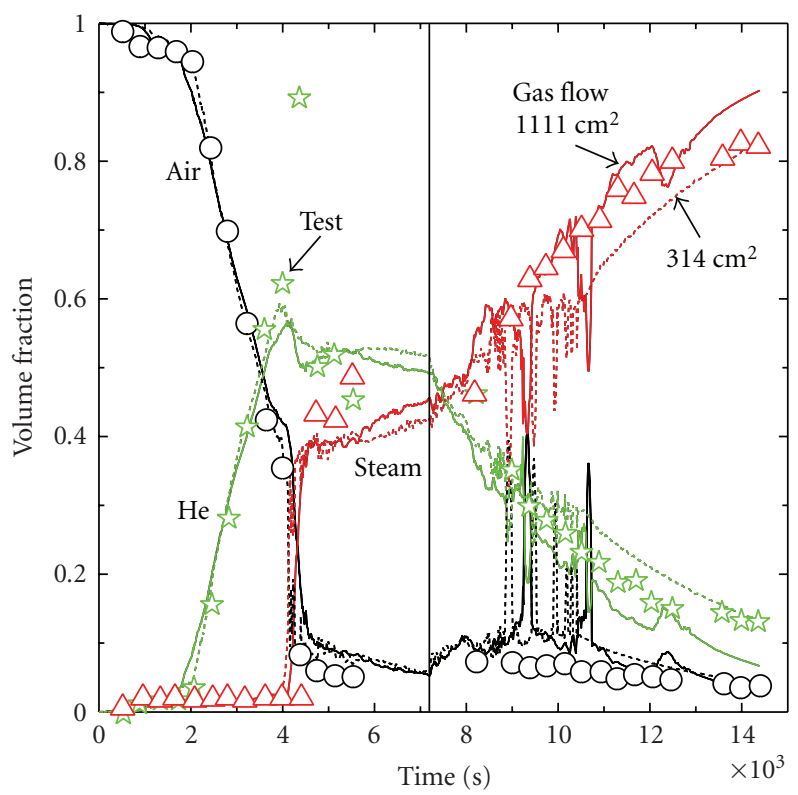

Figure 13: Gas concentrations test 25 at the vent.

effect when the film drains on cold structures, which have a benign potential for film vaporization only. The conditions in test 21bis in which a film drains on a hot surface into dry air is quite different.

The measured concentrations of helium and steam at the vent pipe show helium to arrive 2000 seconds before any steam reaches this location (Figure 13). This earlier arrival of helium far below the injection location is well predicted. It is related to the fact that drying steam/helium/air mixtures on condensing surfaces initially gives locally higher dry 


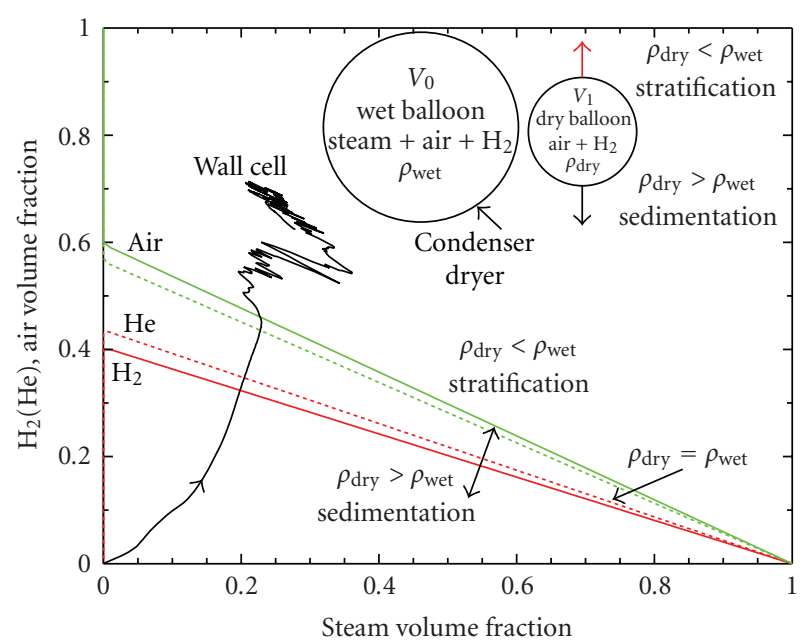

(a)

Equilibrium lines obtained from solving for $\psi_{\mathrm{lg}}$

$$
\begin{aligned}
& \frac{\rho_{\text {wet }}}{\rho_{\text {dry }}}=1=\frac{\left(\psi_{\mathrm{H}_{2} \mathrm{O}} * \mu_{\mathrm{H}_{2} \mathrm{O}}+\psi_{\text {air }} * \mu_{\text {air }}+\psi_{\mathrm{lg}} * \mu_{\mathrm{lg}}\right)}{\left(\left(\psi_{\text {air }} /\left(\psi_{\mathrm{lg}}+\psi_{\text {air }}\right)\right) * \mu_{\text {air }}+\left(\psi_{\mathrm{lg}} /\left(\psi_{\mathrm{lg}}+\psi_{\text {air }}\right)\right) * \mu_{\mathrm{lg}}\right)} \\
& \psi_{\text {air }}=1-\psi_{\mathrm{H}_{2} \mathrm{O}-\psi_{\mathrm{lg}}} \\
& \psi=\text { volume fractions } \\
& \mu=\text { molecular weights } \\
& \lg =\left(\mathrm{H}_{2} \text { or } \mathrm{He}\right), \rho=\text { density }
\end{aligned}
$$

Figure 14: Thought experiment on density changes from drying steam/helium(hydrogen) mixtures.

air/helium densities and causes a local down flow of the dried helium/air mixture next to the wall. As more and more helium is added the dried steam/helium/air mixtures become lighter. Then they rise and contribute to the stratified gas region. A negative buoyancy develops early in test 25 . We call this the condensation sedimentation effect. It is of relevance for all containment applications, where increased hydrogen concentrations are eventually predicted in the lower region during most scenarios [8] because hydrogen release is limited to lower mixture concentrations than in test 25 .

Figure 14 gives the regime map in which steam condensation out of a steam/helium/air mixture can result in a sedimentation (negative buoyancy) or stratification (positive buoyancy) depending on the mixture composition. The equilibrium line for which the dry and the wet mixture have the same density is derived from solving the quadratic correlation in Figure 14 for the light gas volume fraction $\psi_{1 g}$. The correlation holds for drying under constant pressure and temperature condition. It does not depend on the pressure and temperature level. It says that a wet mixture with 20\% steam, 32\% hydrogen, and 48\% air has the same density as the dried mixture, which then has $40 \%$ hydrogen and $60 \%$ air. The concentration development during test 25 in a near wall cell has been entered in Figure 14 with time advancing along the added arrow. It goes through an initial sedimentation phase followed by

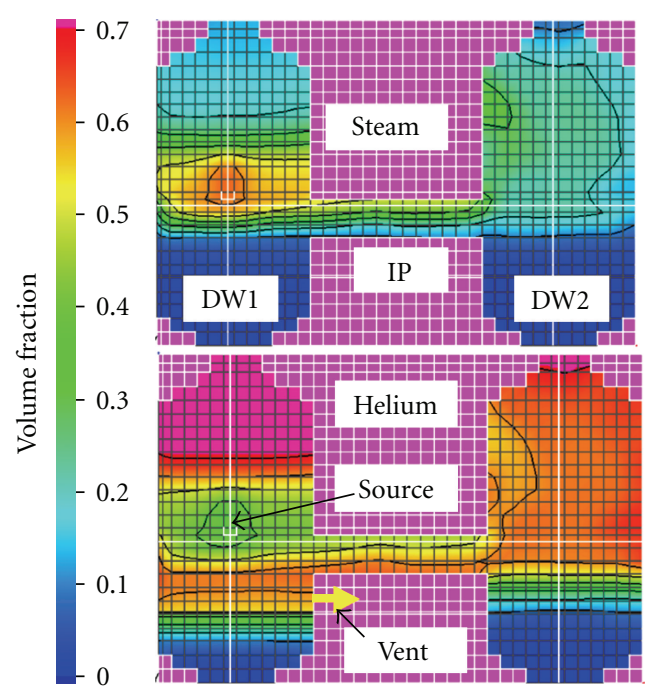

Figure 15: Steam and helium distribution in test 25 at 3700 seconds.

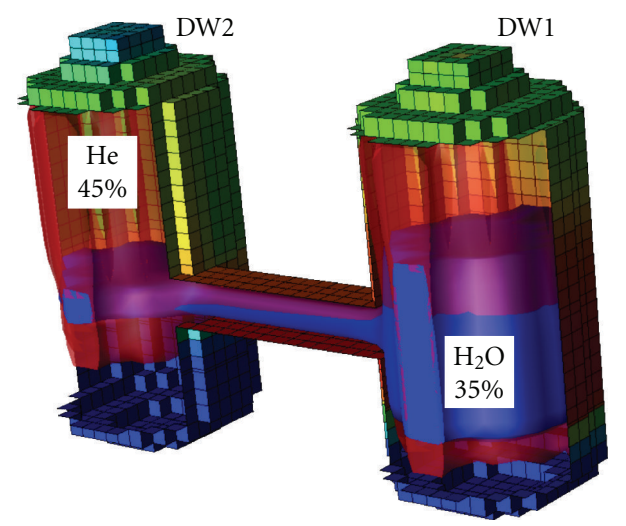

Figure 16: Steam and helium clouds in test 25 near end of helium injection (6600 seconds).

stratification after the helium/steam concentration crosses the $35 / 20 \%$ limit. The data from test 25 validate the predicted hydrogen sedimentation that has been questioned in earlier containment applications with GASFLOW.

During the steam release after 7200 seconds the helium concentration in Figure 13 reduces. The spikes that occur after 7200 seconds come from calculated backflows each time when the rising pressure at the vent exceeds the vessel pressure during a short time leading to a brief inflow of some air and a corresponding reduction in the steam and helium concentration. The steam released after 7200 seconds compresses the stratified helium clouds in DW1 and DW2. It cannot penetrate into the clouds with lighter gas, so their temperatures increase only slightly from the compression. Figure 15 gives more background to the calculated condensation sedimentation effect that causes the earlier arrival of helium at the vent pipe The snap shot shows a central cut of the steam and helium concentration some time before steam arrival at the vent. The helium concentration around the source is lower due 


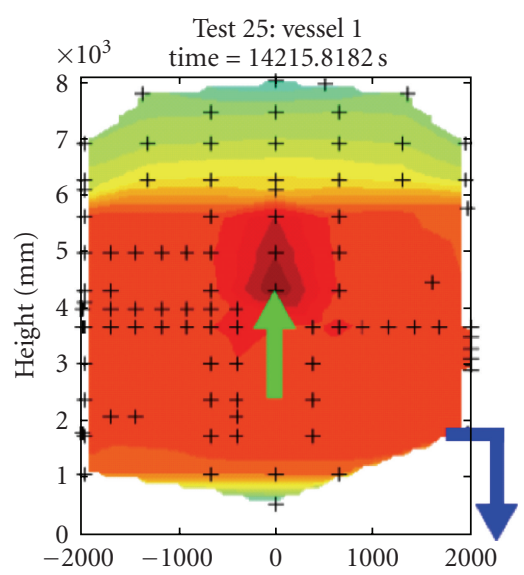

(a)

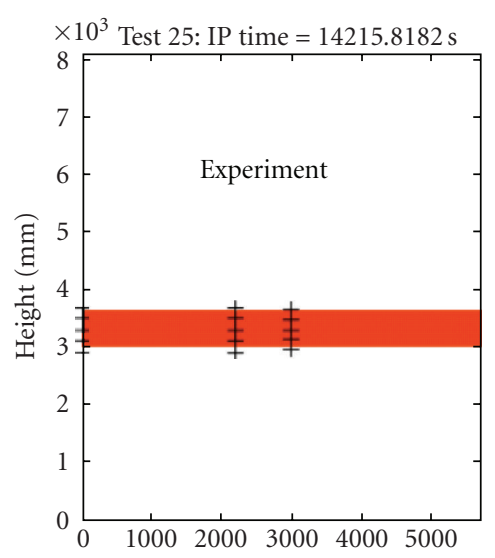

(b)

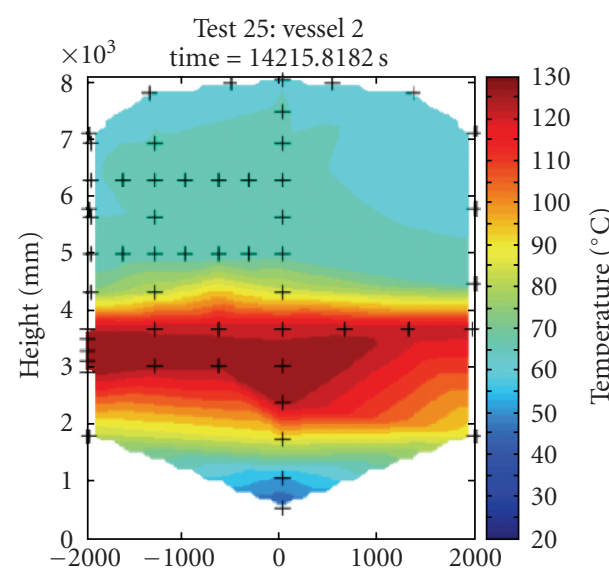

(c)

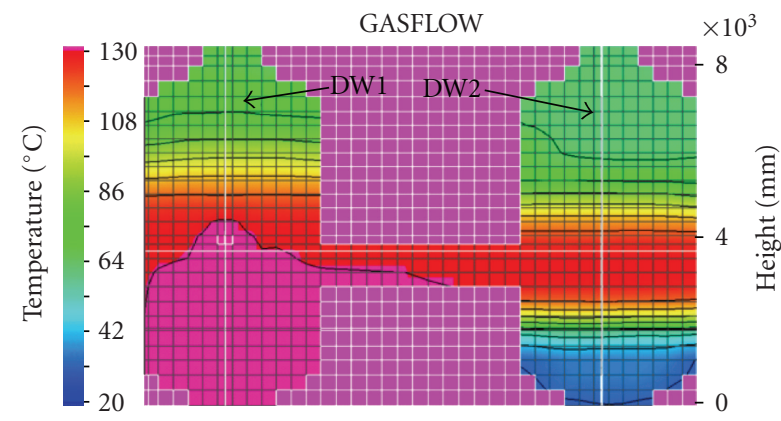

(d)

Figure 17: Final fluid temperatures test 25 at 14400 seconds.

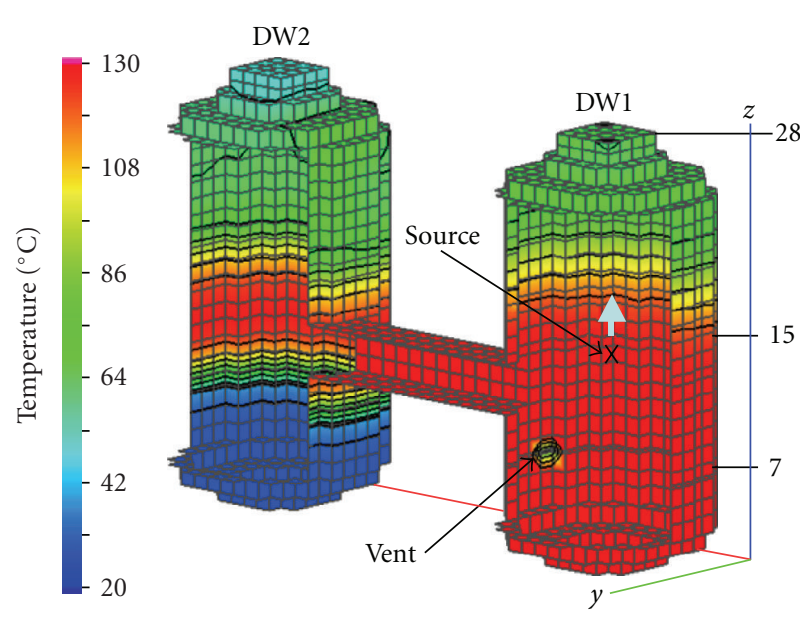

(a)

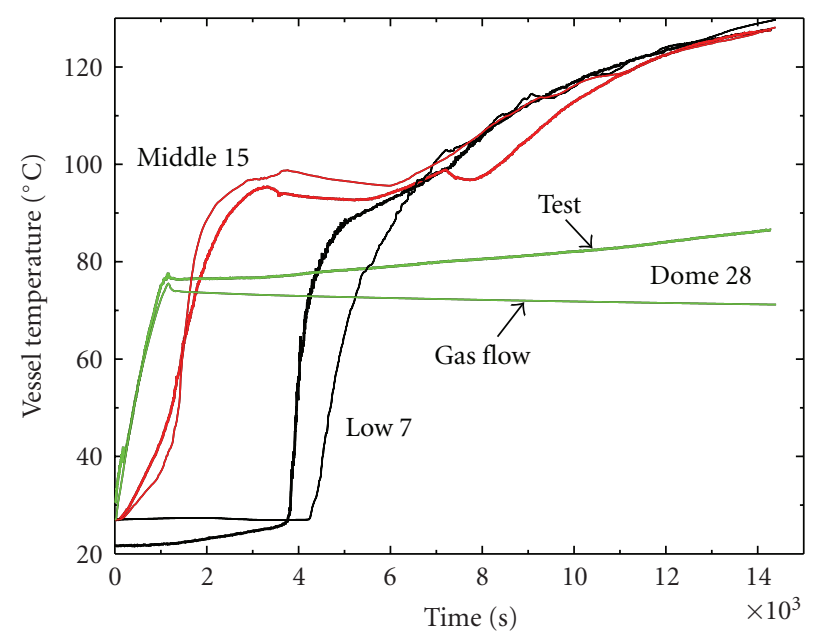

(b)

FIGURE 18: Final structure temperatures test 25 and test data for DW1.

to the steam, but it increases as the steam condenses away from the source and a heavier helium/air cloud with nearly no steam develops in DW1 below the interconnection pipe. The low sensor in Figure 11 records little helium at this time which is in agreement with the test data. The stronger than measured helium increase after 4000 seconds starts when the steam/helium overflow into DW2 has lead to a first equilibrium. Sharp interfaces to the pure air region at the bottom are calculated in GASFLOW and the temporarily higher than measured helium concentrations predicted in the low region of DW1 may be related to the difficulty to catch this lower helium front in phase 1 . The $3 \mathrm{D}$ result animation in Figure 16 with the steam and helium clouds near the end of phase 1 displays this sharp interface in DW1. In the test, it must have occurred at a somewhat higher location. 
Figure 17 compares the calculated and measured final fluid temperatures. The high temperatures indicate the steam regions under the colder region with stratified helium. They are well reflected also in the GASFLOW results. The color scaling differs from the test data, however. The hot steam region is calculated to expand deeper into DW1 than what is shown by the test data and the gas temperature in the dome is somewhat lower than measured. The temperatures in DW2 agree fairly well with the test data. Vessel temperatures in Figure 18 also show low values in the region next to the stratified helium cloud in the dome of DW1 and higher fairly uniform temperatures in the steam cloud underneath. Agreement with the measured data in DW1 is quite good except for the slight increase in the dome region, which is not reflected in the displayed node 28. This GASFLOW node already includes the full heat capacity in the man hole region and cannot follow the temperature increase induced by the gas compression. Figure 18 also shows the applied 3D Cartesian GASFLOW model of the test facility that was simulated adiabatic on the outside as a composite structure with $2 \mathrm{~cm}$ steel and $20 \mathrm{~cm}$ rock wool assuming 1D heat conduction with 44 nodes with 4 nodes in the steel wall and 40 nodes in the insulation. The vessel thickness was doubled in the two uppermost nodes due to the thicker structure in the man hole region. The temperature profile in the structure shows a flat behavior in the steel and a hyperbolic decay toward the outside of the insulation for which only a 10 degree temperature increase is calculated over the simulation period of 14,400 seconds. This demonstrates negligible heat losses in the analyzed test period and justifies the use of the adiabatic boundary condition.

\section{Conclusions}

The GASFLOW simulations for the selected Panda tests 9 and 9bis have shown that in the absence of condensation the results with the finest mesh agree well with other calculations for test 9 at the compared reference time of 250 seconds, yet all give higher than measured temperatures. Coarser meshes locally mix mass, momentum and energy too fast, yet globally they give nearly the same results as the fine mesh. This holds both for tests 9 and 9bis. Convergence of local data could not be reached with the different meshes. But the successful interpretation of tests 9 and 9bis demonstrates that broad atmospheric changes can be captured with coarse meshes quite well. Transient locally heterogeneous conditions will not impact much and do not have to be zoomed with extra-fine meshes. GASFLOW calculations with coarse meshes for test facilities of widely different sizes (up to full containments like HDR in test E11.2) [2] confirm that one can reliably predict thermalhydraulic processes in full reactor containments with such models. The failure to properly determine the volume rates at the vent in test $21 \mathrm{bis}$ indicates that a moving film model may be a desirable feature for implementation. Both tests 9 bis and 21bis are well suited for testing and further improving the steam condensation/vaporization modeling in CFD codes.
Our analysis predicts the high-concentration stable helium layers in test 25 quite well in both DW1 and DW2 that result from the steam condensation out of the source gas mixture on the cold vessel walls. This includes a good simulation of helium accumulation in a dead end compartment, like it is found in many reactor containments. The earlier arrival of helium relative to steam at the vent pipe in test 25 far below the injection source was well predicted. It is related to the fact that steam/helium/air mixtures can temporarily get heavier on condensing walls and give a secondary convection that brings down helium (hydrogen) into the lower region of the containment. As more and more helium is added these dried helium/steam/air layers become lighter and contribute to the stratified gas region. The measured temporary condensation sedimentation effect (motion under negative buoyancy) in test 25 is of relevance also for containment applications. They exhibit such effect in many scenarios because hydrogen/steam injections barely reach high enough hydrogen volume fractions for a condensation stratification. On larger time scales higher hydrogen concentrations are thus often accumulated in the lower rather than in the upper containment regions. Test 25 validates this predicted sedimentation effect from containment analyses with GASFLOW that has sometimes been questioned.

Test 25 also shows up conditions under which one can reach hydrogen clouds with high volume fractions in certain regions of the containment. The composition of the steam/helium source with $36 \%$ helium and $64 \%$ steam is quite representative for certain SBLOCA source terms. The high and potentially sensitive helium volume fraction of $85 \%$ can develop from steam condensation when the steam/helium source fills the dome by expelling air through the vent line. Without venting the source gas mixes with air and the heavy air component effectively drives the atmospheric mixing during steam condensation. Subregions with air displacement can be found in the component rooms of Konvoi-type containments [8] under certain opening conditions of the rupture disks, also in the steam generator boxes of VVER type containments [10] where the communication paths with the dome are not sufficient to circulate the expelled air back through other openings. Such recirculation paths and the amount of air replacement must be considered with more detail in the effected containment regions, with the help of detailed CFD analysis.

The condensation phenomena controlling this test are relevant for all accident scenarios in reactor containments. Their good interpretation backs up the predictive quality of GASFLOW for full containment simulations. The coarse model applied in the simulation of the facility was sufficient for capturing the dominant phenomena. Using the GASFLOW option to strongly reduce the area of the feeding source cell to match the injection momentum turned out to give too much local entrainment at the source so that this parameter should not be applied to inject with the correct momentum in a coarse mesh. The wall functions to describe heat, mass and momentum transfer in a coarse mesh still require further work to arrive at a heat transfer that is mesh independent when approaching stagnant conditions. 


\section{Acknowledgments}

Dr. Michele Andreani from the Paul Scherrer Institute, Switzerland, contributed to this work and gave many details on all experiments and on their current status of interpretation with other CFD codes. He also shared the results from his GOTHIC analysis of test 25 for comparison and solving of open questions from our analysis. This work was partially funded with a research grant from the brain pool program of the Korean government. The authors are also grateful for the financial support of the participating countries to the joint cooperative SETH project run under the auspices of the Nuclear Energy Agency, Organization for Economic Cooperation and Development.

\section{References}

[1] P. Royl, U. J. Lee, Travis, et al., 2007, http://www.gasflow.net/.

[2] P. Royl, P. U. J. Lee, J. R. Travis, and W. Breitung, "Benchmarking of the 3D CFD code GASFLOW II with containment thermal hydraulic tests from HDR and ThAI," in Proceedings of the CFD4NRS Meeting, Munich, Germany, 2006.

[3] O. Auban, R. Zboray, and D. Paladino, "Investigation of large-scale gas mixing and stratification phenomena related to LWR containment studies in the PANDA facility," Nuclear Engineering and Design, vol. 237, no. 4, pp. 409-419, 2007.

[4] D. Paladino, R. Zboray, P. Benz, and M. Andreani, "Threegas-mixture plume inducing mixing and stratification in a multi-compartment containment," in Proceedings of the 12th International Topical Meeting on Nuclear Reactor Thermal Hydraulics (NURETH 12), Pittsburgh, Pa, USA, 2007, abstract no. 195.

[5] M. Andreani, "Comparison between simulations and experiments," in Proceedings of the 9th Meeting of the Program Review Group OECD SETH Project, Villingen, Germany, May 2005.

[6] M. Andreani, K. Haller, M. Heitsch, et al., "A benchmark exercise on the use of CFD codes for containment issues using best practice guidelines: a computational challenge," Nuclear Engineering and Design, vol. 238, no. 3, pp. 502-513, 2008.

[7] M. Andreani, D. Paladino, and T. George, "Simulations of basic gas mixing tests with condensation in the Panda facility using the Gothic code," in Proceedings of the 16th International Conference on Nuclear Engineering (ICONE '08), Orlando, Fla, USA, 2008.

[8] P. Royl, H. Rochholz, W. Breitung, J. R. Travis, and G. Necker, "Analysis of steam and hydrogen distributions with PAR mitigation in NPP containments," Nuclear Engineering and Design, vol. 202, no. 2-3, pp. 231-248, 2000.

[9] P. Royl, J. R. Travis, W. Breitung, J. Kim, T. Kanzleiter, and S. Schwarz, "GASFLOW analysis of steam/hydrogen mixing with nitrogen in the OECD-NEA THAI HM-2 Benchmark," in Proceedings of the NURETH 13, Kanazawa, Japan, SeptemberOctober 2009, paper N13P1412.

[10] U. J. Lee, P. Royl, et al., "Three dimensional analyis of steamhydrogen distribution from a hypothetical small break severe accident in a VVER1000 type reactor containment using GASFLOW II," in Proceedings of the NURETH-10 Conference, Seoul, Korea, 2003. 

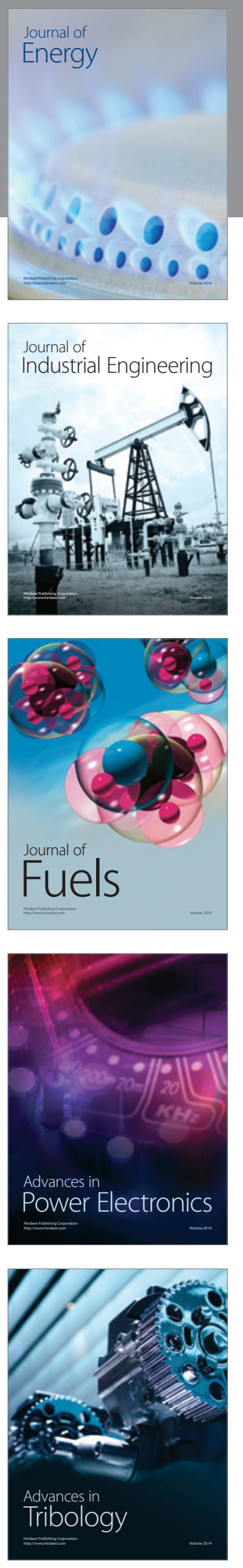
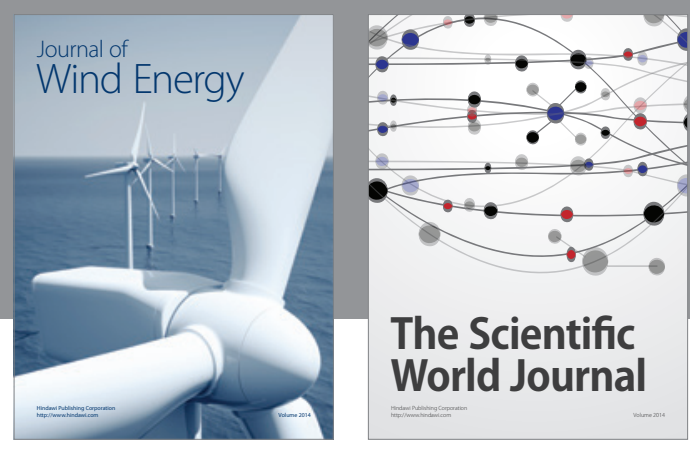

The Scientific World Journal

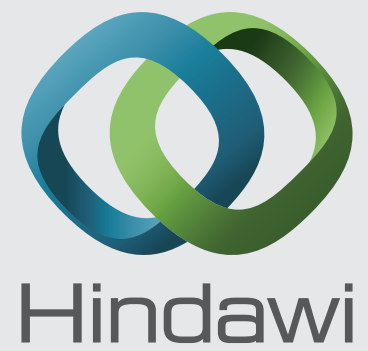

Submit your manuscripts at http://www.hindawi.com
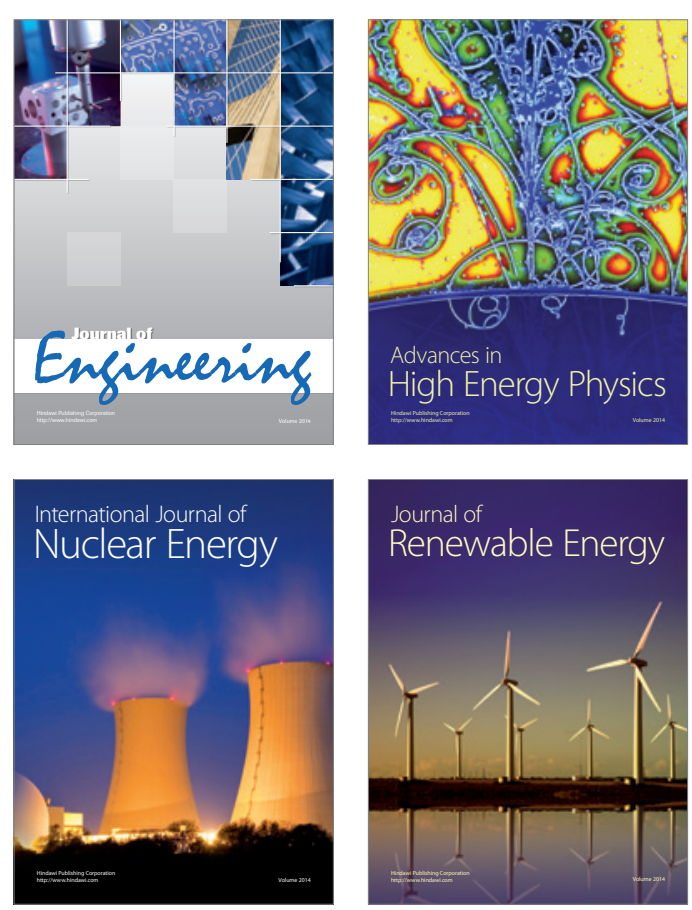

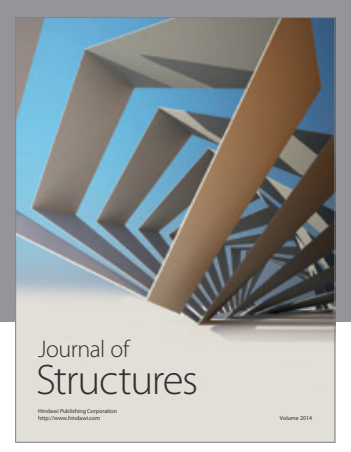

Rotating
Mechinery
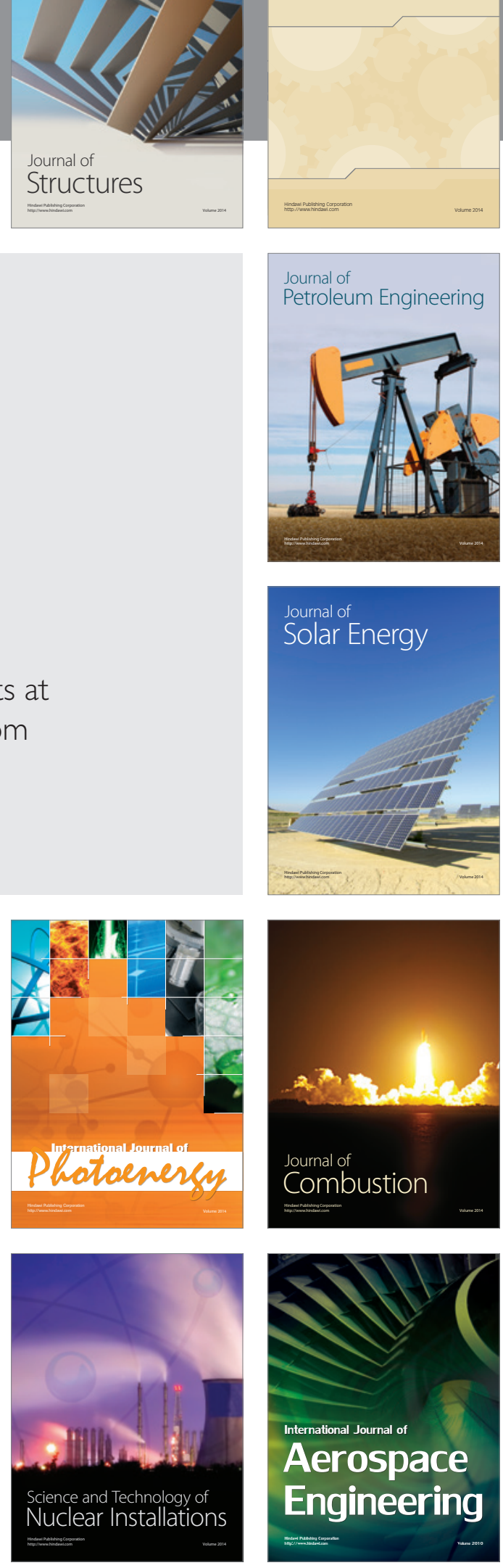